\title{
Comunicação
}

[Communication]

\section{Hemograma e bioquímica sérica auxiliar em bezerros mestiços neonatos e ocorrência de enfermidades}

[Hemogram and auxiliary serum biochemistry in neonatal crossbred calves and disease occurrence]

$$
\text { S.A. Rengifo }{ }^{1} \text {, R.A. Silva }{ }^{2} \text {, R.C.C.M. Botteon }{ }^{3 *} \text {, P.T.L. Botteon }{ }^{3}
$$

\author{
${ }^{1}$ Aluna de pós-graduação - UFRRJ - Seropédica, RJ \\ ${ }^{2}$ Aluno de graduação - UFRRJ - Seropédica, RJ (Bolsista de IC-FAPERJ) \\ ${ }^{3}$ Departamento de Medicina e Cirurgia Veterinária - UFRRJ \\ BR $465, \mathrm{~km} 7$ \\ 23851-970 - Seropédica, RJ
}

\begin{abstract}
O período neonatal é marcado por rápidas e intensas modificações do quadro hematológico, caracterizando-se, ainda, por maior susceptibilidade às doenças. A ingestão de colostro, indispensável à defesa orgânica e sobrevivência do bezerro nos primeiros dias de vida, é considerada uma das mais importantes recomendações nesse período. A falha na ingestão de colostro leva à inanição e ao aumento da suscetibilidade a infecções, com efeitos sobre a mortalidade e a incidência de enfermidades (Todd e White, 1995). Fatores como idade, sexo, raça, nutrição e manejo podem influenciar o quadro hematológico de bovinos (Biondo et al., 1998; Birgel Jr et al., 2001). E, ainda, a condição materna pode ter marcante influência no perfil hematológico e na prevalência de doenças no período neonatal (Kasari e Wilkse, 1994).
\end{abstract}

Este trabalho foi desenvolvido com o objetivo de avaliar alguns parâmetros hematológicos e séricos em 26 bezerros e suas respectivas mães, pertencentes a um rebanho mestiço (HolandêsZebu) no município de Seropédica, RJ, e relacioná-los a enfermidades.

Ao nascer, os animais foram mantidos com as mães por 24 horas, com recomendação ao tratador que efetuasse a cura do umbigo logo após o nascimento. A seguir, foram alojados em baias individuais, com piso cimentado e estrado de madeira sobreposto. A alimentação consistiu de colostro nos três primeiros dias e, logo após, leite integral - 4L/animal/dia -, em duas mamadas até o $10^{\circ}$ dia. A partir da segunda semana, foi oferecido concentrado comercial em comedouro individual, e o mesmo volume de leite, fornecido pela manhã. Os animais, foram mantidos em piquete coletivo de capim-estrelaafricana (Cynodum nelfuensis) durante o dia, permaneceram estabulados à noite até $\mathrm{o}$ desmame aos 56 dias. Diariamente, foram submetidos a exame individual. Amostras de sangue dos bezerros e das vacas, obtidas 24 horas após o nascimento, por punção da jugular (bezerros) e coccígea (vacas), em frascos a vácuo, com e sem anticoagulante (ácido etileno diaminotetracético - EDTA), foram acondicionadas em recipientes com gelo e processadas em até 12 horas. Dos bezerros, novas amostras foram obtidas aos cinco, 15, $30 \mathrm{e}$ 56 dias após o nascimento. Do sangue com EDTA, foram determinadas: a concentração de hemoglobina $(\mathrm{Hb})$, o volume globular (VG), a hematimetria (He) e a leucometria global (LG). Do plasma, obtido por centrifugação, foram determinadas as proteínas plasmáticas totais (PPT) e o fibrinogênio (FB) por refratometria. Do sangue colhido sem anticoagulante, foram obtidas alíquotas de soro, utilizadas para determinação das concentrações de ferro e ferritina, por espectofotometria, utilizando-se kits comerciais. As análises foram realizadas em triplicata, utilizando-se as médias obtidas.

Recebido em 9 de fevereiro de 2010

Aceito em 2 de julho de 2010

*Autor para correspondência (corresponding author)

E-mail: rbotteon@ufrrj.br 
Entre o nascimento e o desmame, 17 bezerros $(65,4 \%)$ adoeceram: quatro (15,4\%) apresentaram um ou mais episódios de diarreia; quatro $(15,4 \%)$ apresentaram processos inflamatórios das estruturas umbilicais e nove $(34,6 \%)$ tiveram diarreia e onfalite. Dois apresentaram descarga nasal mucopurulenta, febre e depressão, e cinco (19\%), alopecia, descamação e crostas de localização circunscrita em áreas da face, pescoço e dorso. O diagnóstico foi confirmado pelo isolamento de Dermatophilus congolensis. Os animais com alterações significativas no estado geral foram medicados segundo cada caso, e não foram registrados óbitos no período.

Índices menores de diarreia seriam esperados em rebanhos cujos bezerros são mantidos com as mães na fase de colostro. Considerando que o manejo e a intensidade de exposição aos patógenos do ambiente podem influenciar a incidência de doenças (Barrington et al., 2003), é provável que os casos de diarreia e onfalite tenham sido decorrentes da alimentação em balde e cura tardia do umbigo, ainda que o tratador tenha sido orientado para efetuar $\mathrm{o}$ tratamento logo após o nascimento. Em condições semelhantes, Miessa et al. (2003) relataram que $64 \%$ dos animais tiveram diarreia e/ou onfalite, e sugeriram, como fatores determinantes, a cura tardia do umbigo e as condições ambientais desfavoráveis.

Os valores hematológicos médios (Tab. 1) encontram-se na faixa de normalidade para bezerros do primeiro ao $30^{\circ}$ dia após o nascimento (Rosenberger, 1993) e estão próximos aos obtidos por Kohayagawa (1993), em bezerros de até 30 dias, e abaixo dos verificados por Peixoto et al. (2002), em bezerros com até 90 dias.

Tabela 1. Valores médios de volume globular (VG), proteínas plasmáticas totais (PPT), fibrinogênio (Fb), hemoglobina $(\mathrm{Hb})$, hematimetria (He) e leucometria global (LG) de bezerros do primeiro aos 30 dias do nascimento e de vacas ao parto

\begin{tabular}{cccccc}
\hline \multicolumn{7}{c}{ Bezerros } & Vacas \\
\hline VG & Dia 1 & Dia 5 & Dia 15 & Dia 30 & $24 \mathrm{~h}$ \\
$\mathrm{PPT}$ & 30,7 & 29,9 & 32 & 32,4 & 30,2 \\
$\mathrm{Fb}$ & 8,2 & 8,1 & 8,1 & 8,4 & 7,9 \\
$\mathrm{Hb}$ & 370 & 440 & 620 & 480 & 475 \\
$\mathrm{He}$ & 8,5 & 8,7 & 8,5 & 11,9 & 9,4 \\
$\mathrm{LG}$ & 6,6 & 5,7 & 5,5 & 5,9 & 5,3 \\
\hline
\end{tabular}

A idade é um fator importante a ser considerado para interpretação do hemograma, especialmente VG, LG e PPT, que, em geral, são influenciados pela absorção do colostro. Os hemogramas seriados revelaram pequenas variações no $\mathrm{VG}$ $(29,9$ a $32,4 \%)$, com valores mais baixos no quinto dia. A hematimetria, normal em todos os exames, foi maior ao nascimento, com decréscimo entre cinco e 15 dias. Essa redução após o nascimento pode ser atribuída à absorção de água do colostro. Não foi verificada influência significativa de fatores etários, a exemplo da redução do número de eritrócitos em função da idade, observada por Kohayagawa (1993) e Dias Jr. et al. (2006), provavelmente devido à diferença de idade entre os grupos e à faixa etária dos animais deste trabalho.

O valor médio de PPT foi $8,2 \mathrm{~g} / \mathrm{dL}$, sendo 11 bezerros com valores acima da média e ligeira variação ao longo do período. As médias foram mais altas que as obtidas por Fagliari et al. (2006), ao avaliarem o proteinograma sérico de bezerros recém-nascidos da raça Holandesa pela técnica de eletroforese em gel de poliacrilamida. Também foram mais elevadas que as médias verificadas por Juliano et al. (2009), para bovinos da raça Curraleiro em diferentes faixas etárias.

A PPT dosada por refratometria fornece uma estimativa indireta da quantidade de imunoglobulinas (Ig) absorvidas. Na ausência de desidratação, uma proteína sérica acima de $6 \mathrm{~g} / \mathrm{dL}$ é indicativo de transferência passiva bemsucedida (Naylor e Kronfeld, 1977). Com base nestes conceitos, a maioria dos bezerros (92\%) teria recebido imunidade passiva adequada. Com o tempo, a concentração de $\mathrm{Ig}$ diminui por degradação catabólica, o que não foi verificado 
até os 30 dias. Valores acima de 8,5g/dL indicam desidratação, contudo a maioria dos autores não cita especificamente os recém-nascidos. Falhas de manejo no período de colostro podem resultar em hemoconcentração, entretanto valores elevados de PPT durante todo o período apontam para adequação no período colostral, contrariando a possibilidade de desidratação.

O fibrinogênio $(\mathrm{Fb})$, ao contrário da LG e PPT, foi maior até os 15 dias. Valores elevados de $\mathrm{Fb}$ são indicativos de processos inflamatórios. Nessa faixa etária, o exame clínico revelou a presença de onfalite e/ou diarreia em 17 bezerros, o que pode justificar a elevação do fibrinogênio. Os leucócitos totais com valores mais elevados aos 30 dias, segundo Jain (1986), estavam na faixa da normalidade durante todo o período, porém mais baixos que os obtidos por Kohayagawa (1993) e Peixoto et al. (2002), em bezerros de diferentes idades, e por Biondo et al. (1998), em bezerros entre um e 30 dias.

A hemoglobina variou de 8,5 a $11,9 \mathrm{~g} / \mathrm{dL}$, sendo mais elevada aos 30 dias, mas sem diferença significativa. O conteúdo de hemoglobina está, assim como o hematócrito, em estreita associação com o número de eritrócitos. Os níveis normais ficam entre 8 e $15 \mathrm{~g} / \mathrm{dL}$. Valores baixos são indicativos de anemia, e elevados indicam hemoconcentração. A elevação da $\mathrm{Hb}$ após 15 dias reforça a ideia de que a deficiência de ferro não deve ser a causa provável de anemia em animais com acesso ao pasto, uma vez que a disponibilidade de ferro nas forrageiras é suficiente para atender à demanda dos bovinos (McDowell, 1999).

Ao nascimento, três bezerros (11,5\%) apresentaram VG abaixo de $24 \%$, os quais também apresentaram $\mathrm{He}$ e $\mathrm{Hb}$ subnormais. Em quatro $(15,4 \%)$, a $\mathrm{Hb}$ estava baixa, porém o VG e a He normais. Um deles apresentou o hemograma normal no quinto dia, e os demais continuaram com valores baixos até o $15^{\circ}$ dia. Considerando que valores baixos de $\mathrm{He}, \mathrm{Hb}$ e/ou VG caracterizam anemia (Jain, 1986), sete animais (26,9\%) estavam anêmicos ao nascimento. Aos cinco, 15 e 30 dias, respectivamente, oito $(30,7 \%), 15(68,2 \%)$ e 11 $(42,3 \%)$ animais apresentaram valores hematológicos indicativos de anemia. Após esse período, o número se reduziu a 10 devido à venda dos machos. Ao desmame (56 dias), quatro animais (40\%) estavam com VG, He e/ou $\mathrm{Hb}$ abaixo da normalidade.

Anemia é, em geral, resultante da combinação de múltiplos fatores. Em bezerros, a incidência no período neonatal oscila entre 15 e $30 \%$, e a gravidade varia segundo as reservas ao nascimento, a taxa de crescimento pós-natal e a fonte adicional de ferro (Raleish e Wallace, 1962). Os casos de anemia registrados ao nascimento $(26,9 \%)$ e aos cinco dias $(30,7 \%)$ estão dentro da expectativa para neonatos. Contudo, entre $15(68,2 \%)$ e 30 dias $(42,3 \%)$, os índices ficaram acima dos apontados pela literatura.

Considerando o acesso ao pasto, a suplementação a partir da segunda semana e a pequena possibilidade de infestação parasitária relevante na faixa etária estudada, sugere-se que a anemia esteja relacionada ao manejo nutricional das matrizes e à qualidade do colostro. Diarreia crônica pode prejudicar a absorção de ferro, contudo a maioria dos casos teve resolução em até cinco dias, não sendo provável a influência da diarreia sobre a incidência de anemia.

Os valores médios de Fb, LG e PPT das vacas, 24 horas após o parto, foram normais, e próximos aos valores dos bezerros, ao nascimento. Treze vacas $(54,2 \%)$ estavam com anemia. Embora próximas, a $\mathrm{He}$ e a $\mathrm{Hb}$ foram mais baixas, e o VG mais elevado que os relatados por Ferreira et al. (2009), para bovinos do grupo-controle e submetidos ao estresse calórico.

A deficiência nutricional de ferro e cobre ou a má utilização do ferro disponível na dieta poderia, em parte, ser avaliada pelos valores séricos de ferro e ferritina, o que não foi confirmado em relação ao ferro, cujas médias de 138,8 e $110,5 \mu \mathrm{g} / \mathrm{dL}$, respectivamente, para vacas e bezerros ao nascimento, estiveram dentro dos limites descritos para a espécie (Meyer et al., 1995). A ferritina, que reflete diretamente estoque de ferro no organismo, diminui na anemia ferropriva, antes que sejam detectadas alterações do ferro sérico (Cook, 1999). A média de ferritina $(476,5 \mu \mathrm{g} / \mathrm{dL})$ foi normal para os bezerros e baixa $(259,2 \mu \mathrm{g} / \mathrm{dL})$ para as vacas. Dois bezerros (8\%) e 11 vacas (46\%) apresentaram valores inferiores a $300 \mu \mathrm{g} / \mathrm{dL}$. Sete vacas apresentaram VG e/ou He também baixos. 
Os valores baixos de ferritina em $46 \%$ das vacas podem estar relacionados ao aumento da necessidade na gestação, à absorção deficiente decorrente da carência de cobre, comum na região, ou à perda decorrente de infestação por carrapatos.

$\mathrm{VG}, \mathrm{Fb}, \mathrm{Hb}$ e $\mathrm{He}$, ao nascimento, foram mais baixos e LG, mais elevada, entre os animais que não adoeceram. Aos 15 e 30 dias, todos os parâmetros foram normais e não diferiram entre animais sadios e enfermos. Os resultados contrariaram a expectativa de que enfermidades seriam mais frequentes em animais com anemia e reforçam a possibilidade de que o manejo esteja relacionado à elevada incidência de diarreia e onfalite.

Palavras-chave: bezerro leiteiro, hemograma, anemia

\begin{abstract}
Packed cell volume, hematimetry, hemoglobin, total leukocyte, total plasmatic protein, fibrinogen, iron, and ferritin values were evaluated in 26 calves on days 1, 15, 30, and 56 after birth. In addition, calves were also observed during the parturition date. The data were evaluated according to disorders noticed by daily monitoring. Seventeen calves (65.4\%) exhibited clinical signs and nine did not get ill. The main illnesses were diarrhea and omphalitis. Erythrogram, leukogram, plasmatic proteins, and fibrinogen were within the reference ranges, although a meaningful variation was observed relating age and fibrinogen. Individually, seven (26.9\%) calves were anemic at birth. Moreover, anemia was also noticed in eight (30.7\%) five-day-old animals and 15 (68.2\%) and 11 (42.3\%) animals on days 15 and 30, respectively. The parameters recorded in the cows were within the medium range and close to the calves. Thirteen (54.2\%) cows presented packed cell volume and/or hematimetry under the normal ranges. Plasmatic iron was normal to the cows $(139 \mu \mathrm{g} / \mathrm{dL})$ and also to the calves $(110 \mu \mathrm{g} / \mathrm{dL})$. On the other side, ferritin was normal for calves $(476 \mu \mathrm{g} / \mathrm{dL})$ and below the range for cows $(259 \mu \mathrm{g} / \mathrm{dL})$. If is concluded that the high index disorders between calves was not related to the evaluated parameters.
\end{abstract}

Keywords: dairy calf, hemogram, anemia

\section{REFERÊNCIAS BIBLIOGRÁFICAS}

BARRINGTON, G.M.; GAY, J.M.; EVERMANN, J.F. Biosecurity for neonatal gastrointestinal diseases. Vet. Clin. N. Am.: Food Anim. Pract., v.18, p.27-34, 2002.

BIONDO, A.W; LOPES S.T.A.; KOHAYAGAWA, A. et al. Hemograma de bovinos (Bos indicus) sadios da raça Nelore, no primeiro mês de vida, criados no estado de São Paulo. Cienc. Rural, v.28, p.251-256, 1998.

BIRGEL JUNIOR, E.H.; D'ANGELINO, J.L.; BENESI, F.J. et al. Valores de referência do eritrograma de bovinos da raça Jersey criados no estado de São Paulo. Arq. Bras. Med. Vet. Zootec., v.53, p.1-9, 2001.

COOK, J. The nutritional assessment of iron status. Arch. Latinoam. Nutr., v.49, p.115-145, 1999.

DIAS JR., R.F.; BRACARENSE, A.P.F.R.L.; MARÇAL, W.S. et al. Valores de referência e influência da idade no eritrograma de fêmeas bovinas da raça Aquitânica. Arq. Bras. Med. Vet. Zootec., v.58, p.311-315, 2006.
FAGLIARI, J.J.; RIZOLLI, F.W.; SILVA, S.L. et al. Proteinograma sérico de bezerros recémnascidos da raça Holandesa obtido por eletroforese em gel de poliacrilamida. Arq. Bras. Med. Vet. Zootec., v.58, p.450-453, 2006.

JAIN, N.C. Schalm's Veterinary Hematology. 4.ed. Philadelphia: Lea \& Febiger, 1986. p.655675.

JULIANO, R.S.; FIORAVANTI, M.C.S.; FAGLIARI J.J. et al. Proteinograma sérico de bovinos da raça Curraleiro. Arq. Bras. Med. Vet. Zootec., v.61, p.533-538, 2009.

FERREIRA, F.; CAMPOS, W.E.; CARVALHO, A.U. et al. Parâmetros clínicos, hematológicos, bioquímicos e hormonais de bovinos submetidos ao estresse calórico. Arq. Bras. Med. Vet. Zootec., v.61, p.769-776, 2009.

KASARI, T.R.; WILKSE, S.E. Perinatal mortality in beef herds. Vet. Clin. N. Am.: Food Anim. Pract., v.10, p.1-185, 1994. 
KOHAYAGAWA A. Aspectos laboratoriais $e$ testes de imunofluorescência indireta (IFI) para Babesia bovis, B. bigemina $e$ Anaplasma marginale em bezerros da raça holandesa (Bos taurus) naturalmente infectados, 1993. 140f. Tese (Doutorado) - Faculdade de Medicina Veterinária e Zootecnia, Universidade Estadual Paulista, Botucatu, SP.

McDOWELL, L.R. (Ed). Minerais para ruminantes sob pastejo em regiões tropicais, enfatizando o Brasil. 3.ed. Gainesville: University of Florida, 1999. 92p.

MEYER, D.J.; COLES, E.H.; RICH, L.J. Medicina de laboratório veterinário interpretação e diagnóstico. São Paulo: Roca, 1995. 308p

MIESSA, L.C.; AMARAL, A.; BOTTEON, R.C.C.M. et al. Morbidade e mortalidade de bezerros leiteiros devido a processos inflamatórios do cordão umbilical. Hora Vet., v.23, p.16-18, 2003.
NAYLOR, J.M.; KRONFELD, D.S. Refractometry as a measure of the immunoglobulin status of the newborn dairy calf. J. Am. Vet. Med. Assoc., v.171, p.1331-1334, 1977.

PEIXOTO, A.P.C.; COSTA, J.N.; KOHAYAGAWA, A. et al., Hemograma e metabolismo oxidativo dos neutrófilos de bovinos da raça Holandesa preta e branca. Rev. Bras. Saúde Prod. Anim., v.3, p.16-20, 2002.

RALEISH, R.J.; WALLACE, J.P. The influence of iron and copper on hematologic values and on body weight of range calves. Am. J. Vet. Res., v.23, p.276-299, 1962.

ROSENBERGER, G. Exame clínico dos bovinos. 3.ed. Rio de Janeiro: Guanabara Koogan, 1993.

TODD, A.G.; WHYTE, P.B.D. The effect of delays in feeding colostrum and the relationship between immunoglobulin concentration in the serum of neonatal calves and their rates of growth. Austr. Vet. J., v.72, p.415-417, 1995. 